PAMELA PETRUSKA GATICA RAMÍREZ

ESCUELA DE DISEÑO

UTEM

SANTIAGO, CHILE

PETRUSKA@GMAIL.COM

Fecha de recepción: 3/01/2018

Fecha de aceptación: 28/03/2018

Cómo citar: GATICA, P. (2018)

Dinámica teórica del fundamento emocional (lo vivo) en el diseño (lo cultural).

RChD: creación y pensamiento, 3(4), 1-9.

DOI: 10.5354/0719-837X.2018.49519

Revista Chilena de Diseño,

RChD: creación y pensamiento

Universidad de Chile

2018, 3(4)

http://rchd.uchile.c

\section{Dinámica teórica del fundamento emo- cional (lo vivo) en el diseño (lo cultural)}

Theoretical dynamics of the emotional basis (the alive)

in design (the cultural)

Resumen. Este artículo es una aproximación teórica a los aspectos que surgen de considerar la emoción como un fundamento en el diseño, siendo posible delimitar cuatro ámbitos teóricos; los que se han denominado dinámicos por la naturaleza de lo humano y la cultura; es decir, lo emocional involucra la comprensión de un cuerpo vivo que "se mueve", y de un escenario que estará siempre "en movimiento". Desde esta perspectiva, se establece por parte del diseño una propuesta cultural al evidenciar relaciones emoción-diseño dentro de las diferentes etapas del proceso, del producto y evaluación de los objetos o artefactos. Lo que vincula la actividad proyectual a la observación responsable hacia los otros y hacia sí mismo; provocando un espacio para la reflexión y la autorreflexión al problematizar el acto de diseñar y los productos del diseño.

El cruce referencial de los cuerpos de conocimiento del diseño basado en la emoción y las teorías de la emoción configuran un mapa que permite delimitar territorios propios del diseño en cuanto a problemáticas teóricas, resumidos en la trayectoria misma del diseño como disciplina, el pensamiento, la cultura y la sociedad. Estos ámbitos podrían estar configurando una propuesta cultural en la que el diseño reflexiona y actúa en consecuencia con el ámbito de lo emocional y su repercusión en la sociedad, otorgando relevancia en la cultura su propio quehacer, así como la interacción de las personas y artefactos de uso.

Palabras clave: cultura, emoción, teoría del diseño.

Abstract. This article is a theoretical approach to the aspects that arise from considering emotion as design basis, making possible to delineate four theoretical areas; called dynamic attending the nature of the human and culture; that is, emotional involves the understanding of a living body that "moves" and a scenario that will always be "in motion".

From this perspective, a cultural proposal is established by design, evidencing emotion/design relationships within the different stages of the process, the product and evaluation of objects or artifacts. What causes a linkage of projectual activity with responsible observation towards others and oneself; eliciting a space for reflection and self-reflection when the act of designing and the products of design are a study problem.

Crossing bodies of knowledge between emotion based design and theories of emotion produce a map that allows us to delimit design territories concerning theoretical issues, summarized in the trajectory of design as a discipline, knowledge, culture and society.

These areas could be configuring a cultural proposal in which design reflects and acts accordingly to the emotional sphere and its repercussion in society, granting relevance to its own task within culture, as well as the interaction of people and artifacts.

Keywords: culture, design theory, emotion. 


\section{Introducción}

Cuando entendemos el campo del diseño como una actividad proyectual que se extiende al mundo de las cosas y de las personas que usan y significan esas cosas, o artefactos, vinculamos propiedades intrínsecas del ser humano, del ser vivo. Lo afectivo le ofrece al diseño la problematización del acto de diseñar y de los productos de diseño, siendo que no solo adquieren un aspecto formal y de uso, sino también de significado, con un alcance mayor de lo puramente significativo. La oportunidad de la percepción y valoración posible de la condición vital (lo emocional, el patior) a través del proceso proyectual (lo mental, el logos).

La concepción de emoción, como característica biológica fundamental del ser humano, se articula junto a los complejos procesos de vida y de pensamiento. Se proyecta, en el acto del ser humano como individuo; y se refleja en el acto del ser humano como ser social. Dentro de la cultura 'aparece' nombrando la cualidad 'vital' del hombre. Esta cualidad del ser emocional complementa la visión del ser racional, otorgándole características asociadas a la naturaleza, los ciclos vitales y el movimiento.

La vinculación del diseño y la emoción se sitúa en ámbitos de desarrollo dinámicos que intercambian la reflexión y el análisis de los diferentes procesos de cada uno de ellos. Permite la observación de variaciones -en constante movimiento- dentro de las personas y culturas, dado por las complejas e infinitas articulaciones que se pueden obtener de las relaciones que ofrece la emoción cuando es incluida como una variable.

El diseño y la emoción construyen un relieve cultural de los artefactos de uso, sea cual sea su índole, en relación a lo vivo como fundamento insoslayable de la cultura humana.

\section{Metodología}

La elaboración de una propuesta teórica en torno a la vinculación del diseño y emoción proviene de una investigación transdisciplinaria cualitativa documental que consistió en el análisis de conceptos y descripciones, para establecer límites teóricos de la conceptualización del término emoción vinculados a la cultura y el diseño. Este extenso trabajo fue realizado para la tesis doctoral "Diseño y emoción. La vinculación de dos conceptos como propuesta cultural", en la Universitat de Barcelona, el año 2015.

Se estudiaron textos sobre diseño y emoción de autores relevantes, como Chapman, Desmet, Gobé, Hekkert, Jordan, Norman, Mcdonagh, Schifferstein, Van Erp, entre otros; sumado al estudio de trabajos presentados en los congresos de la Sociedad, Diseño y Emoción que se realizaron periódicamente desde el año 1999 al 2017, de los que se revisó material del 1999, 2002 y de los años 2004 a 2010. Se pudo observar variaciones en torno al uso del concepto emoción, más que en el desarrollo conceptual del término, en la configuración propia de modelos y experiencias basadas en la emoción, en su mayoría expuestas para el desarrollo de productos de consumo. De esta información se construyó una clasificación tipológica de la vinculación conceptual diseño-emoción.

Por otra parte, el estudio de la teoría de la emoción desde los ámbitos científicos y filosóficos arrojó una conceptualización determinada por los enfoques metodológicos de estudio, abarcando las denominadas teorías del sentir, y aquellas teorías que conjugan las perspectivas cognitiva y conductual; siendo relevantes, además, las teorías que se desprenden de las 
concepciones anteriores y adquieren sentido cuando relacionan aspectos culturales, como la idea de un ser humano con emociones de fondo compartidas por las comunidades y grupos de comunidades en general.

El cruce conceptual de la teoría de la emoción con las tipologías de vinculación conceptual que denominamos 'diseño-emoción' permitió establecer el marco de discusión teórica que se plantea a continuación.

\section{Emoción-diseño: ámbitos teóricos dinámicos}

La condición dinámica de la emoción, ya sea como una tendencia a la acción (Maturana y Pörksen, 2004), una respuesta fisiológica a un estímulo (Calhoun y Salomon, 1989) o el sentimiento de lo que acontece (Damasio, 2001), en directa referencia a lo vivo, provoca 'movimiento' en la cultura. Dinámica que genera, y se percibe a través de los artefactos creados. La trayectoria histórica de nuestra cultura (occidental) ha visto reforzado el pensamiento de la razón lógica, lo que determina las posibilidades explicativas del mundo. Así como el dominio objetivo de la materia viva, que se desenvuelve en diferentes procesos limitados por tiempo y espacio.

Inserto en la cultura, la cotidianidad humana es parte del dominio principal reconocible hoy en día en el diseño. Desde el escenario urbano ha ido formando parte de las dinámicas culturales de las ciudades, vinculando el concepto de emoción a su quehacer para determinar diferentes acciones proyectuales, desarrollar artefactos y argumentos teóricos de pensamiento que, si bien no determinan por completo su propio quehacer, se conjugan con las particularidades de la cultura en la que se desenvuelve.

El diseño-emoción ofrece reflexión y análisis de los procesos, metodologías y productos, mediante condiciones que fluctúan y extralimitan los alcances conceptuales del término emoción y, al mismo tiempo, van modificando estos alcances dentro de cada ámbito.

Las dinámicas que se exponen están delimitadas como campos para la problemática teórica del hacer y discurso del diseño-emoción, recogidas como un mapa territorial de convergencias de la conceptualización de la emoción y su uso en el diseño. El diseño, el pensamiento, la cultura y la sociedad son los cuatro ámbitos que se exponen de manera general, para situar en cada uno de ellos algunos aspectos particulares de la problemática.

Dinámica del diseño. Ámbito en que el diseño-emoción transita junto a las variables de la lógica del proceso (propias del diseño) y la del progreso (de revoluciones industriales, determinantes del quehacer del diseño) que provienen del trayecto histórico de la disciplina y su relación con lo emocional. En el ideal de progreso asociado a la revolución industrial, sobresale el paradigma de la máquina y lo social. La racionalidad se sobrepone ante todo para el objetivo principal: el progreso como factor de bienestar social. Este bienestar social es azotado por los cambios producidos a nivel económico y político. En la efervescencia por una mayor producción combinado a la aparición de nuevas disciplinas -como el psicoanálisis-, la devastación de dos guerras mundiales, entre otros factores, se produce una tendencia a la mirada del individuo como agente social de producción.

El diseño desde sus características modernas se halla vinculado a la idea de progreso para el bienestar social y humano, por lo que orienta su mirada al proceso de diseño para la industrialización con la creación de técnicas y metodologías para la racionalización y control del proceso creativo (Jones, 1982; Munari, 2006). 
Desde la perspectiva de progreso capitalista, las cualidades emocionales pueden ser entendidas como un capital social que beneficia a la sociedad en general (Wurkmir, 1964, p. 140).

La racionalización evidencia la importancia del espacio temporal que representa el proceso, en el que el diseñador es un agente que transforma realidad mediante artefactos cuya proyección va más allá de lo meramente funcional, pues aunque ello suceda, reflexiona (Žižek, 2005).

Esta reflexión surge del proceso de diseño, en donde piensa aquello que se le presenta como un problema formal que resolver; la práctica le hace conjugar observaciones y resultados para 'pensar' su proyectar. Se piensa el proceso y los artefactos que resultan.

En el contexto histórico, la lógica del progreso sufre un golpe de timón que lo condiciona a teñir sus discursos de un nuevo paradigma, entendiendo que el escenario de la globalización 'resitúa' la idea del hombre, el capital y su desarrollo social.

En el paradigma hacia una nueva gestión del hombre privado, la temporalidad adquiere relevancia, no existe un antes o después definitivamente delimitado, sino un continuum que abre y cierra, avanza y retrocede, se adelanta y recoge. Este flujo de actividad neuronal permite la comprensión de lo 'no lineal' en el proceso de adquisición de conocimiento, así como de las condicionantes para 'hacer' constantemente, es decir para la actividad racionalizada.

El proceso, pues, se torna parte de la nueva lógica. Se incluye todo aquello que forma parte de lo observable, más allá de lo cuantificable o no, en un determinado lapso y espacio. Se adscribe al exceso de información y al signo inequívoco de lo efímero del conocimiento por encima de lo perdurable del aprendizaje. Lógica 'del proceso' en donde la cotidianidad adquiere relevancia. Esta complejidad que reflexiona el diseño obliga integrar al pensamiento aquello que se siente (Sennet, 2009, p. 18). En donde el diseño-emoción hacen posible una relación dialéctica entre el proceso de diseño y el objeto (Martí, 1999), y a su vez, una relación dialéctica de la presencia del objeto y la persona.

Dinámica del pensamiento. Ámbito que viene dado por el diseño-emoción que recoge la comprensión del pensamiento como un aspecto escindido de la emoción, en el que se originan dos enfoques: el objetivo y subjetivo. El pensamiento es entendido como una cualidad reflexiva del ser humano, y discurso de conocimiento mediante el cual se producen las representaciones, las identificaciones y las conceptualizaciones resultantes. De la escisión de mente y cuerpo se desprende lo subjetivo y objetivo, mientras que la comprensión de una mente que elabora pensamiento en consonancia con los procesos emocionales desdibuja los límites de esta comprensión (Damasio, 2001); por lo tanto, (re)articula la relación dialéctica entre los objetos y las personas.

Entre estas dualidades se debate el diseño: lo objetivo como vecino de lo argumental, racional, comparte lugar con lo subjetivo. Se define en el terreno de lo racional, del conocimiento científico por una parte y, por otra, emotivo, asociado a lo intuitivo e irracional, lo que dotaría de cualidades humanizadoras al pensamiento de diseño (Buchanan, 1995, p. 50).

El pensamiento resulta imposible de desarrollarse sin el sustrato emocional. La emoción, que determinaría lo subjetivo del pensamiento, se adhiere a las modalidades sensoriales, de movimiento y afecto físico, determina cualidades al quehacer del diseño, y a su pensamiento dentro de la cultura.

La determinación racionalista, en la que se ha de reducir los elementos a expresiones mínimas, factibles de cuantificar o medir, para ser incluidos en 
la dinámica económica o comercial, ha llevado a acentuar la inclinación propia de la razón para el control no solo del proceso, sino también de los objetos, los artefactos. Cosas que se perciben y 'viven' las afecciones de las interacciones con las personas.

Las racionalización organiza y desplaza elementos para la argumentación y las convenciones de significado. Aunque se debiera tener en cuenta que lo propio de la razón se ordenaría libremente hacía al bien, al vincularse al "sentimiento moral" que fundaría toda norma general, incluidas las económicas (Smith, 1978, p. 99).

Desde otra vereda, las escuelas gestálticas unen aquello que por partes pierde sentido. La forma es comprendida como un objeto dentro del pensamiento y no como objeto el pensamiento en sí. El cuerpo entero es el que piensa, además del cerebro, uniendo cosas y pensamientos en una sola unidad, vinculándose recíprocamente y adquiriendo sentido como un todo (Fernández, 2004, p. 97).

El diseño-emoción reconoce la dualidad en la que se desenvuelve, desde el dominio objetivo al albedrío subjetivo, como una unidad en la que objetos y pensamientos se conjugan. Acepta la idea racionalista que resuelve separar las partes, para nombrarlas y, de ese modo, hacerlas parte de una percepción controlada, invariable, atemporal, dominada. Sumando la posibilidad de patrones emocionales, cuya complejidad y temporalidad son imposibles de ser dominados invariablemente.

Dinámica de la cultura. Aspecto que circunscribe al diseño-emoción como actividad proyectual que da forma y, al mismo tiempo, nombra dentro de lo 'sentido'. El lenguaje se sitúa en la comunicación en un sustrato cognitivo, que podría diferenciarse de la emoción en la medida que las emociones operan en todo el estar humano, con la complejidad que ello conlleva.

La relación íntima entre lenguaje y emoción forma parte del proceso de razonamiento para la comunicación que va acompañado de la experiencia sensorial y la memoria emotiva. Solemos pensar en palabras y son estas las que configuran cuerpos de significado para la relación humana y la comunicación cultural. La visión holística del lenguaje, en el que se da una visión estructural de los fenómenos apela a una visión sincrónica en la que se maneja la relación de los elementos en su conjunto, configurándose una interrelación simultánea y pluridireccional de los elementos lingüísticos.

Los objetos son nombrados como artefactos desvinculados del continuum vital humano; no obstante, bajo el fundamento emocional el lenguaje adquiere cualidades metafóricas que permiten que la forma evidencie la(s) emoción(es), "el sentimiento es una forma” (Fernández, 1994, p. 95). Esto implica las variaciones interculturales asociadas al lenguaje y a las consideraciones emocionales de cada cultura.

El 'vivir' en el lenguaje configura las dinámicas de significado en lo psicológico y lo social, presentando una problemática a la hora de objetivizar sus componentes para la observación. Lakoff y Johnson nos advirtieron de los mitos existentes en la configuración del uso del lenguaje planteado como el objetivismo se ha conformado una idea de ser racional y por su contraparte, el subjetivismo forma parte de lo irracional o el "dejarse llevar por las emociones" (Lakoff y Johnson, 1980, p. 231).

Desde el diseño, la forma se entiende dentro de un proceso. Se acepta la noción que mediante la técnica se obtiene la forma (Alexander, 1986, p. 139), 
pero también es dentro de la temporalidad del proceso que existe esta, el camino hacia ella también es relevante, por lo que el lenguaje actúa desde el proceso y posteriormente en los resultados formales finales.

La imposibilidad de poder contener el significado de las emociones en el lenguaje, inevitablemente conduce a otras manifestaciones del género humano. Es por tanto la forma una de las maneras de representar las emociones. Desde la forma aparece contenida una experiencia reflejo de nuestras experiencias vívidas, en las que la forma encarna aquella manifestación. No obstante, para los efectos de comunicar, y dado que el lenguaje no resulta del todo efectivo, la forma se traslada al lenguaje, en forma de metáfora. Desde esa perspectiva, el mundo se hace representable emocionalmente desde la forma y el tropo. Las formas tienen la facultad de hablar por las personas, no a través de las palabras, sino por medio de la encarnación de las intenciones del que las crea y observa. Nombrar las emociones mediante la palabra no alcanza para objetivizar un componente psicobiológico tan difícil de asir, estas se viven entrelazadas a los pensamientos, sin la posibilidad de crear una distancia para tener un marco claro de observación. En este sentido, la palabra diaria, aquella que se dice 'sin pensar', parte del lenguaje cotidiano, está mucho más cerca de la afectividad. También esto explica la causa que las expresiones fisiológicas emocionales suelen describirse en imágenes o ilustraciones.

El hablar cotidiano establece un mundo posible en el que las interacciones comunicativas varían de voces de un idioma a otro, de matices de un territorio a otro. Creando, además, aspectos semánticos que hablan de 'modos' diferentes de percibir y vivir (sentir) el mundo. Estas variaciones del lenguaje verbal, y no verbal, van más allá de los significados diversos; son aspectos del conocimiento propio de una cultura que se puede comprender en la medida que se interactúe en el hábitat de un lenguaje y personas determinado.

El diseño-emoción adopta la responsabilidad del lenguaje en el proceso y en la forma final del proceso, ya sea un artefacto $u$ otro producto, evidenciando su relevancia para el desarrollo de la acción proyectual. Un lenguaje que, según cada cultura, no solo nombra sino que viene afectado del sentir de las personas y comunidades.

Dinámica del ser social. La felicidad y el sufrimiento. La compasión y la admiración. El diseño-emoción recoge en este aspecto la comprensión de las emociones sociales para el acto proyectual.

El ser humano, como individuo y como ser social, se mueve en una dinámica en donde las emociones negativas y positivas adquieren relevancia como aspectos que se comparten en comunidad. La felicidad y el sufrimiento, pasan a ser concepciones culturales que se sociabilizan y que sostienen gran parte de la dialéctica social como parte de las necesidades humanas, en donde la admiración y la compasión son sus respuestas.

Csikszentmihalyi plantea que la felicidad es un estado que se produce a través del disfrute. En la experiencia 'óptima' bajo la condición del flow, la capacidad humana de concentrar su atención hacia una determinada actividad, y que genera conciencia, permite prevalecer el 'disfrute' en la ejecución de esa actividad; reduciendo la condición natural del hombre de entropía psíquica (Csikszentmihalyi, 1999).

La perspectiva de la felicidad tiene su cara opuesta, en la que la experiencia es negativa. No obstante, el diseño suele apostar por la felicidad -o las emociones positivas- en una cultura que ensalza ese sentimiento en función de 
la anulación del patior. El alcance de la felicidad se mantiene como una meta cultural occidental, que se asocia al bienestar, en parte de la cultura oriental; en cambio, se tiene una visión orientada a armonizar estos opuestos.

El diseño desde su preocupación por lo cotidiano recoge este interés por el bienestar en un estado de felicidad; no obstante, también lo expone a reconocer aquello que está en el desasosiego (Mallol, 2012), en la incomodidad, la agitación, más allá de lo estrictamente plácido y feliz.

La compleja relación que se crea entre razón y emoción, al mismo tiempo que individualización, a través de la historia va construyendo un ser social que va desarrollando estas primeras 'enseñanzas' en torno a la pasión. De modo que el individuo 'aparece' reconstruido. Esta máscara que cubre las pasiones trata de ser liberada en la época del romanticismo, situación que más adelante se conjugará con la mirada introspectiva a la psique individual en el siglo XX. La cultura que se vive permeabiliza la individualidad e incluso el ánimo, el modo de afectarse y de sentir. Abre un amplio espectro para explotar los sentimientos, enlazándolos a los productos de diseño, ya sean para la comunicación o artefactos de uso, mediante la fascinación de la técnica audiovisual o la tecnología que (hiper)estimula los sentidos.

La tendencia del ser humano, de ser social, de vivir en el lenguaje y construir realidad desde su hábitat y cultura, se encuentra en un escenario pleno de individualidad, comprendiendo que ciertas cualidades emocionales son atributos que le recuerdan la necesidad de contacto social y de retroalimentación afectiva, a lo que el diseño atiende por su vinculación con lo afectivo.

\section{Emoción y artefactos: espacio para la comprensión y reflexión del proceso de diseño}

Como se ha dicho, la vinculación del concepto emoción con el diseño configura un escenario dinámico, los artefactos pasan a conformar todas aquellas relaciones subjetivas que tiene el ser humano desde su experiencia sensorial, y que lo mueve permitiéndole relacionarse con el mundo de una manera vívida, traspasando esas cualidades a su propio entorno y viceversa.

El diseño entonces adquiere un 'compromiso' mediante una actitud que no solo le permite racionalizar el proceso de diseño, sino también reflexionar sobre él y sobre el artefacto. Resuelve comprender el entorno de una manera más formal, en el sentido de las formas y sus atributos significativos. Desde los diferentes ámbitos, la cotidianidad humana enfrenta la práctica del diseño a una instancia compleja en la que se produce una dinámica 'viva' que confluye con los artefactos. La relación de los artefactos, en cuanto representaciones de objetos proyectados, y las personas, se sucede en un ámbito en el que se le asigna significado y forma a aquello que funciona como estímulo sensible. Las modalidades sensoriales, las relaciones cognitivas que se establecen con las emociones en nuestra vida diaria, sumado al hecho de una relación 'recreada' para hacer énfasis en esa cualidad de lo vivo, de lo afectivo, generan experiencias en movimiento, que van construyendo realidad y hábitos.

Eva Illouz ilustra desde las relaciones de emoción y el consumo el como "[...] la materialidad concreta y específica de los productos se desvanece en el reino intangible de los sentimientos" (IIlouz, 2009, p. 127).

Lo que viene a ser una situación en la que los objetos y artefactos cobran un sentido que va más allá de sus cualidades funcionales y de uso, a atributos complejos, propios de la biología y psique humana.

Es en esta complejidad que se visualizan las emociones y la tecnología, 
apostando a que la inteligencia artificial pueda descifrar todos esos millones de combinaciones afectivas que se suceden en el cotidiano humano (Scheirer y Picard, 2000; Trappl et al., 2003). El traspaso de una cualidad humana a la inteligencia artificial, podría ser considerado entonces como el control máximo de la concepción de emoción. Recurriendo al modelo cerebral, símbolo de la cultura contemporánea que sucede al corazón (Martin, 2008), como un modelo de conexión y operativo para resolver cuestiones de carácter 'emocional'.

\section{Conclusiones}

Los espacios para la problemática teórica expuestos, el diseño-emoción transita determinado por las cualidades culturales en las que aparece la totalidad de lo humano biopsicológico individual (en un marco social) como un proceso de apropiación emocional de los artefactos de uso empleados. Las cualidades de lo dinámico, de 'una tendencia a', de una lógica atemporal y una predeterminación cultural en la valoración afectiva, se tornan relevantes en la cultura y en la interacción de las personas y artefactos de uso.

El diseño, por su parte, desde la perspectiva del proceso y metodologías, así como de instrumentos y técnicas, incluye la emoción como un concepto que ha ido delimitando un ámbito para su actividad.

Cuando el diseño introduce y vincula las cualidades de lo emocional al proceso de diseño y al artefacto adquiere un compromiso que lo situará en un rol en el que posibilita reconocer las formas emocionales del entorno y de sus habitantes. El ser humano como observador de las emociones, como ser empático de las emociones de otros y como auto-observador de sus propias emociones. Teniendo en cuenta que la cultura humana está fundada en el cambio (Groys, 2008), la posibilidad de enrolarse en el papel de observador y auto-observador vendría a recuperar el compromiso de solucionar desde la forma, entendiéndola como un elemento que está en constante cambio y representa las cualidades emocionales del ser humano.

El diseño-emoción es una visión humanística del diseño, colocando la verdad de la relación entre sujetos y objetos en la experiencia emocional, proponiendo soluciones de diseño que vayan dirigidas a las emociones de los usuarios. En este contexto, emerge como una de las soluciones propuestas de la disciplina del diseño a problemas de la cultura del consumo. Si bien la lógica del mercado es rápida para realzar el potencial de la experiencia emocional como un nuevo valor para ser atribuido a los productos, surge la sospecha, de tanto en tanto, que diseño y emoción puedan ser uno de los valores que la ideología del consumo explota.

La tarea de crear experiencias es confiada a un conjunto de intermediarios culturales que están ubicados en posiciones estratégicas dentro del sistema de consumo. Todos apuntan a controlar y manipular las condiciones y variables que tienen efectos positivos en la demanda de ciertos productos. Los límites de riesgo no ocurren solo cuando los productos son diseñados para demostrar una gran apariencia emocional o enriquecer la experiencia sensorial, por poner ejemplos de aplicación, sino cuando el consumidor actual está siendo diseñado paulatinamente como un ser emocional. La propuesta cultural del diseño-emoción sugiere la posibilidad de una autorreflexión crítica que permita seguir creciendo y conversando con su propio quehacer, así como su rol en la sociedad y diálogo con otras disciplinas. 


\section{Referencias}

Alexander, Ch. (1986). Ensayo sobre la síntesis de la forma. ( $5^{\mathrm{a}}$ ed.). Buenos Aires: Infinito.

Buchanan, R., \& Margolin, V. (Eds.) (1995). Discovering design. Explorations in design studies. Chicago:

The University of Chicago Press.

Calhoun, Ch., \& Solomon, R. (1989). ¿Qué es una emoción? México: FCE.

Csikszentmihalyi, M. (1999). Fluir (Flow). Una psicología de la felicidad ( $7^{\mathrm{a}}$ ed.). Barcelona: Kairós.

Damasio, A. (2001). El error de Descartes: La emoción, la razón y el cerebro humano. Barcelona: Crítica.

Fernández Christlieb, P. (2004 [1890,1940,1990]). Metodología de la afectividad colectiva. En Mendoza, J., \& González, M. A., Enfoques contemporáneos de la Psicología Social en México: de su génesis a la ciberpsicología (pp. 87-118). México: Tecnológico de Monterrey.

Groys, B. (2008). Bajo sospecha. Una fenomenología de los medios. Valencia: Pre-textos.

Illouz, E. (2007). Intimidades congeladas. Las emociones en el capitalismo. Buenos Aires: Katz.

Jones, Ch. (1982). Métodos de diseño ( $3^{\mathrm{a}}$ ed.). Barcelona: Gustavo Gili.

Lakoff, G., \& Johnson, M. (1980). Metáforas de la vida cotidiana. Madrid: Cátedra.

Mallol Esquefa, M. (2012). Experiencia como inquietud. ProyectoDiseño (Decálogos del Diseño), 82, 257-284.

Martí, J. M. (1999). Introducció a la metodologia del disseny. Barcelona: Edicions de la Universitat de Barcelona.

Martin Høystad, O. (2008). Una historia del corazón. Desde la antigüedad hasta la actualidad. Buenos Aires: Ed. Lengua de Trapo.

Maturana, H., \& Pörksen, B. (2004). Del ser al hacer: Los orígenes de la biología del conocer ( $2^{\mathrm{a}}$ ed.). Santiago: .

Scheirer, J., \& Picard, R. (2000). Affective objects. Massachusetts: MIT Media lab Technical Rep.

Sennet, R. (2009). El artesano. Barcelona: Anagrama.

Smith, A. (1978). Teoría de los sentimientos morales. México: FCE.

Trappl, R., et al. (2003). Emotions in Humans and Artifacts. Massachusetts: MIT Press.

Žižek, S. (2005). Design as an ideology. Ponencia presentada originalmente en ERA05: The World Design, Congreso en Copenhague (Septiembre). 